\title{
Nutritional Complications and the Management of Patients with Gastroenteropancreatic Neuroendocrine Tumors
}

\author{
Erin Laing ${ }^{a, b} \quad$ Nicole Kiss $^{b}$, $d$ e $\quad$ Michael Michael $^{c} \quad$ Meinir Krishnasamy $^{b}, f$ \\ a Department of Nutrition and Speech Pathology, Peter MacCallum Cancer Centre, Victorian Comprehensive Cancer \\ Centre, Melbourne, VIC, Australia; ${ }^{b}$ Department of Nursing, School of Health Sciences, The University of Melbourne, \\ Melbourne, VIC, Australia; ' Department of Medical Oncology and Neuroendocrine Unit, Peter MacCallum Cancer \\ Centre, Victorian Comprehensive Cancer Centre, Melbourne, VIC, Australia; ${ }^{d}$ Institute for Physical Activity and \\ Nutrition (IPAN), School of Exercise and Nutrition Sciences, Deakin University, Burwood, VIC, Australia; ${ }^{\text {}}$ Department \\ of Cancer Experiences Research, Peter MacCallum Cancer Centre, Victorian Comprehensive Cancer Centre, \\ Melbourne, VIC, Australia; ${ }^{f}$ Victorian Comprehensive Cancer Centre, Melbourne, VIC, Australia
}

\section{Keywords}

Neuroendocrine tumor · Nutrition · Malnutrition · Diet ·

Niacin

\begin{abstract}
Neuroendocrine tumors (NETs) have increased in incidence and prevalence over the past 2 decades and affect approximately 170,000 people in the United States alone. Gastroenteropancreatic (GEP) NETs (GEP NET) are a heterogeneous group of rare tumors that have distinct effects on the body due to their tumor location and potential to secrete hormones and peptides. Clinical practice guidelines and consensus guidelines for GEP NETs with regard to best practice for diagnosis, treatment, and medical management are available, but the supportive care needs and optimal nutritional management of patients affected by these unique tumors remain under-researched: evidence to guide clinical practice is lacking. The pathophysiology of the disease and its treatment can cause various symptoms that can have significant effects on vitamin synthesis and absorption, dietary habits, weight change, and appetite. Deficiency of fat-soluble vitamins and niacin exists amongst patients with GEP NET, particularly those on treatment with somatostatin ana-
\end{abstract}

karger@karger.com www.karger.com/nen

(c) 2019 S. Karger AG, Base

Karger' logs and with serotonin-secreting tumors, respectively. Malnutrition and dietary modification amongst patients with GEP NET is more prevalent than initially thought: up to $25 \%$ of inpatients with GEP NET are malnourished. Food intolerance is also reported in up to $40-90 \%$ of these patients, though its misdiagnosis is common. This review summarizes the evidence regarding the impact of GEP NET and its treatment on nutritional factors in these patients with emphasis on malnutrition, vitamin deficiencies, dietary intake, and quality of life. Recommendations for clinical practice and research approaches to address these nutritional issues are discussed.

(c) 2019 S. Karger AG, Basel

\section{Introduction}

Neuroendocrine tumors (NETs) are a heterogeneous group of tumors, most commonly located in the gastrointestinal system and lung [1]. Incidence and prevalence of NETs has increased significantly in the past 2 decades [2], and the prevalence of NETs is currently greater than other gastrointestinal cancers (gastric, pancreatic, esophageal, hepatobiliary adenocarcinomas) [2,3]. Gas- 
trointestinal NETs or gastroenteropancreatic (GEP) NETs account for around $60 \%$ of all diagnosed cases and are located in the small intestine, pancreas, and colon; and less commonly in the stomach $[3,4]$. GEP NETs are considered a rare and complex disease requiring specialized multidisciplinary consultation and management $[3$, $5,6]$.

Patients with GEP NETs can experience numerous and complex symptoms relating to the local and systemic sites of their disease, paraneoplastic hormonal syndromes or various treatment modalities [7, 8]. Symptoms are often related to the hypersecretion of hormones and peptides (such as serotonin, gastrin, glucagon, and insulin) which can lead to specific hormonal hypersecretory syndromes such as carcinoid syndrome, diabetes mellitus, hypoglycemia, and hypergastrinemia (Zollinger-Ellison syndrome) $[3,9]$. These syndromes can hence lead to fatigue, secretory diarrhea, flushing, and abdominal discomfort $[8,10]$. The complex pathophysiology, symptoms, and treatment of NETs thus have the potential to significantly impact a patient's nutritional status through their effects on dietary intake, digestion, and nutrient absorption.

Research indicates that patients with GEP NET may be at risk of various nutritional issues including nutrient malabsorption, vitamin deficiencies, food intolerance, and malnutrition. Recent review articles have discussed the nutritional impacts of NETs and suggested that nutrition is an essential component of the assessment and management of these patients $[11,12]$. The impact of body composition and metabolic syndrome on NETs and patient outcomes was a particular focus of these reviews though not all literature related to nutrition and NETs was discussed. A comprehensive and detailed evaluation of all available nutrition-related literature is warranted, as is the provision of evidence-based nutrition recommendations for all aspects of nutrition including nutritional status, diet, and vitamin deficiencies. In preparation for this review a literature search was undertaken up to February 2019 to obtain published literature for original clinical studies, observational studies, systematic reviews, and meta-analyses using the following databases: MEDLINE, PubMed, EMBASE, and CINAHL. A keywordbased search was performed using various terms in combination (neuroendocrine tumor OR carcinoid OR neuroendocrine cancer $\mathrm{OR}$ neuroendocrine carcinoma) AND (gastrointestinal OR GEP OR pancreatic OR gut OR intestine* OR colorectal OR colon) AND (malnutrition OR nutrition OR diet* OR food OR vitamin OR niacin OR weight OR malabsorption). A total of 676 articles were found and their abstracts assessed for eligibility. Ar- ticles were deemed eligible for inclusion if they reported data related to nutrition (malnutrition, diet, food, vitamins or symptoms) and GEP NETs. Only articles published in English were included for analysis. Reference lists from eligible articles were manually searched to identify further relevant articles. A total of 13 original or observational studies, 3 narrative reviews, and 1 published abstract met the eligibility criteria. No systematic reviews or meta-analyses met the eligibility criteria. This review provides a comprehensive overview of current available literature and knowledge regarding the nutritional complications of patients with GEP NETs. The state of evidence guiding an approach to screening and management of nutrition issues is discussed along with current recommendations for practice.

\section{Symptoms and their Nutritional Impacts}

Symptoms experienced by patients with NET can result from the tumor mass effect (from primary or metastases), generalized symptoms of malignancy, side-effects of hormonal hypersecretion or related to side-effects of the patient's cancer treatment $[3,6]$. Side-effects related to GEP NET, including those with a potential to impact nutrition, are summarized in Table 1 . The most prevalent reported symptoms in patients with GEP NET include diarrhea, fatigue, abdominal discomfort, flushing, and food intolerance (Table 2). Up to $30 \%$ of patients with GEP NETs, in particular mid-gut NETs (located in the jejunum, ileum, and proximal colon), have carcinoid syndrome, whereby their tumors secrete serotonin and other endogenous amine hormones $[6,13]$. Such hypersecretion can give rise to symptoms of flushing $(70-80 \%$ of cases), fatigue, severe secretory diarrhea (50-80\% of cases), food intolerance, restlessness, and fluctuations in mood and pain ( $40 \%$ of cases) $[6,8,14,15]$. NET-related symptoms can persist for prolonged periods, both predating and after the diagnosis, and these symptoms have a significant impact on the patients' well-being with the potential to markedly reduce QOL $[8,16-21]$.

There are various treatment modalities used for disease and symptom control in patients with GEP NETs, and include surgery (curative or debulking), somatostatin analog treatment (SSA: lanreotide or octreotide), chemotherapy, peptide-receptor targeted radiotherapy, and targeted therapies such as everolimus and sunitinib [13]. Each of these treatments has the potential to cause sideeffects and symptoms that impact QOL and nutritional health (Table 3 ). 
Table 1. Effects of GEP NET on symptom presentation $[3,6,8]$

Presence of malignancy

Fatigue

Low appetite

Weight loss

General malaise

Nausea

Tumor mass

primary tumor metastasis

Pain Pain

Organ dysfunction Organ dysfunction

Low appetite Liver: pain, nausea, fatigue, loss of appetite, fever

Peritoneum: pain, bowel obstruction, ascites, bleeding

Lung: shortness of breath, cough

Lymph nodes: pain, compression of adjacent structure causing dysfunction

\begin{tabular}{llll}
\hline Tumor location & & & \\
\hline small intestine & colon/rectum & pancreas & stomach \\
\hline Bowel obstruction & Bowel obstruction & Altered blood glucose & Early satiety \\
Bowel ischemia & Bowel ischemia & Altered exocrine enzyme function & Abdominal pain \\
Nutrient malabsorption & Diarrhea & Nutrient malabsorption & Reflux/heartburn \\
Steatorrhea & Abdominal pain & Diarrhea & Bleeding \\
Diarrhea & Bleeding & Steatorrhea & Obstruction \\
Abdominal pain & & Abdominal pain & \\
Bleeding & & Biliary obstruction & \\
\end{tabular}

\begin{tabular}{|c|c|c|c|c|c|}
\hline $\begin{array}{l}\text { serotonin } \\
\text { (carcinoid) }\end{array}$ & $\begin{array}{l}\text { insulin } \\
\text { (insulinoma) }\end{array}$ & $\begin{array}{l}\text { gastrin } \\
\text { (gastrinoma) }\end{array}$ & $\begin{array}{l}\text { glucagon } \\
\text { (glucagonoma) }\end{array}$ & $\begin{array}{l}\text { vasoactive intestinal } \\
\text { peptide (VIPoma) }\end{array}$ & $\begin{array}{l}\text { somatostatin } \\
\text { (somatostatinoma) }\end{array}$ \\
\hline Flushing & Hypoglycemia & Peptic ulceration & Hyperglycemia & Severe diarrhea & Diabetes \\
\hline Fatigue & Dizziness & Abdominal pain & Glucose intolerance & Hypokalemia & Cholelithiasis \\
\hline Diarrhea & Headache & Diarrhea & Diarrhea & Dehydration & Steatorrhea \\
\hline Food intolerance & Weakness & Heartburn & Weight loss & & Diarrhea \\
\hline Pain & Confusion & Weight loss & Necrolytic & & Weight loss \\
\hline Small bowel ischemia & Loss of consciousness & Bleeding & migratory erythema & & \\
\hline
\end{tabular}

Carcinoid heart disease

Pellagra

GEP NET, gastroenteropancreatic neuroendocrine tumors.

Diarrhea is a common and burdensome side-effect of GEP NETs that impacts functional and social wellbeing $[6,10,15,22]$. Underlying causes of diarrhea can be multifactorial and include malabsorption of bile acids and fat due to surgical resection, SSA treatment, pancreatic insufficiency, or tumoral hypersecretion of serotonin (Fig. 1) [15].

\section{Nutritional Issues in Patients with GEP NETs}

\section{Vitamin Deficiencies}

Some studies have explored the potential impact of GEP NETs and their treatment on vitamin synthesis and absorption, with emerging data indicating a risk of niacin and fat-soluble vitamin deficiency in some patients [2326]. These deficiencies can be a result of several factors 
Table 2. Studies reporting symptom prevalence (\%) in patients with GEP NET

\begin{tabular}{|c|c|c|c|c|c|c|c|c|c|}
\hline Study & Diagnosis, sample size & $\begin{array}{l}\text { Diarrhea, } \\
\%\end{array}$ & $\begin{array}{l}\text { Steatorrhea, } \\
\%\end{array}$ & $\begin{array}{l}\text { Fatigue, } \\
\%\end{array}$ & $\begin{array}{l}\text { Food } \\
\text { intolerance, \% }\end{array}$ & $\begin{array}{l}\text { Flushing, } \\
\%\end{array}$ & $\begin{array}{l}\text { Abdominal } \\
\text { pain/cramps, } \%\end{array}$ & $\begin{array}{l}\text { Weight } \\
\text { loss, } \%\end{array}$ & $\begin{array}{l}\text { Appetite } \\
\text { loss, } \%\end{array}$ \\
\hline $\begin{array}{l}\text { Frojd et al. } \\
{[19], 2007}\end{array}$ & Carcinoid tumor $(n=59)$ & 50 & - & 69 & - & 53 & 50 & - & 39 \\
\hline $\begin{array}{l}\text { Fiebrich et al. } \\
{[24], 2010}\end{array}$ & $\begin{array}{l}\text { Carcinoid tumor, on SSA } \\
(n=35)\end{array}$ & - & 23 & - & - & - & - & - & - \\
\hline $\begin{array}{l}\text { Singh et al. } \\
\text { [17], } 2016\end{array}$ & $\begin{array}{l}76 \% \text { GI NET/pNET } \\
12 \% \text { lung NET }(n=1,928)\end{array}$ & 48 & 19 & 56 & - & 37 & 41 & 21 & - \\
\hline $\begin{array}{l}\text { Lind et al. } \\
\text { [26], } 2016\end{array}$ & SI NET, post-surgery $(n=50)$ & $88-92$ & 48 & - & - & - & $24-48$ & - & $8-12$ \\
\hline $\begin{array}{l}\text { Borre et al. } \\
{[48], 2018}\end{array}$ & $\begin{array}{l}66 \% \text { GI NET/pNET } \\
20 \% \text { lung NET }(n=186)\end{array}$ & 27 & - & - & - & - & 22 & - & - \\
\hline
\end{tabular}

GEP NET, gastroenteropancreatic neuroendocrine tumors; SSA, somatostatin analog; GI, gastrointestinal; pNET, pancreatic NET; SI, small intestinal.

Table 3. Symptoms associated with treatment modality $[3,6,36]$

\begin{tabular}{|c|c|}
\hline \multicolumn{2}{|l|}{ Surgery } \\
\hline Bowel resection & $\begin{array}{l}\text { Diarrhea, steatorrhea, nutrient malabsorption, short gut syndrome, bacterial overgrowth, } \\
\text { dehydration }\end{array}$ \\
\hline \multicolumn{2}{|l|}{ Targeted therapy } \\
\hline SSA & $\begin{array}{l}\text { Abdominal pain/cramps, nausea, constipation, pancreatic insufficiency, diarrhea, } \\
\text { steatorrhea, fat malabsorption, fatigue }\end{array}$ \\
\hline PRRT & Nausea, vomiting, pain (immediately post-treatment), carcinoid syndrome flare \\
\hline Chemotherapy & Fatigue, nausea, vomiting, low appetite, diarrhea, constipation, mucositis \\
\hline
\end{tabular}

related to GEP NETs including depletion of internal stores or malabsorption related to serotonin hypersecretion, and treatment modalities including surgical resection and SSAs. Studies investigating the prevalence of vitamin deficiencies in patients with GEP NET are summarized in Table 4.

\section{Niacin}

Evidence is emerging on the impact of serotonin-producing NETs on niacin (vitamin B3) deficiency and risk of pellagra $[23,25]$. In healthy individuals, niacin is synthe- sized from the amino-acid tryptophan [27]. In the presence of a NET, serotonin is synthesized preferentially to niacin, potentially leading to deficiency (Fig. 2) [23, 27-31].

The impact of over-production of serotonin on niacin status in people with NETs has been examined by several researches since the 1960s [29, 30, 32]. Previously it has been reported that between 5 and $20 \%$ of patients with serotonin-producing NETs or carcinoid syndrome present with clinical features of pellagra [32,33]. The actual prevalence of biochemical or "sub-clinical niacin deficiency" may be as high as $30-45 \%$ [23]. Two studies have examined 
Fig. 1. Causes and impact of diarrhea in GEP NETs. Steatorrhoea, bowel disturbance characterized by pale, oily, and floating stools, often associated with diarrhea. SSA, somatostatin analog.

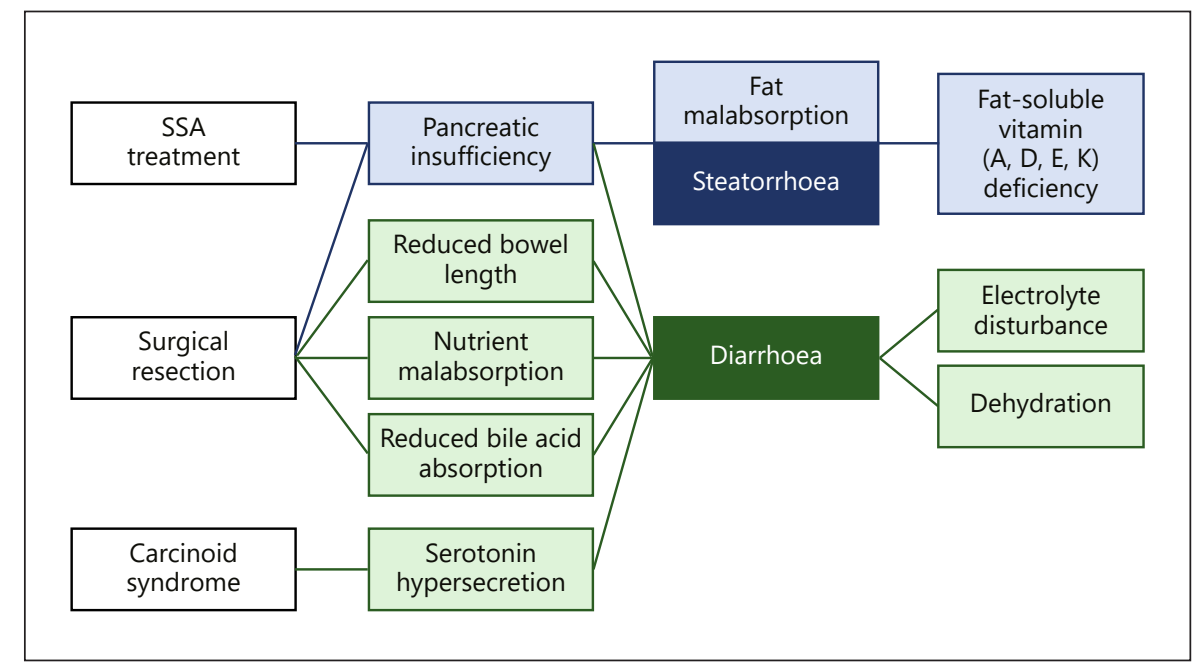

the prevalence of niacin deficiency in patients with GEP NETs (Table 4) [23, 25]. The first study by Shah et al. [23], conducted in the United States and Canada, found that $28 \%(n=36)$ of NET patients newly diagnosed with carcinoid syndrome had serum niacin deficiency, whereas rates of deficiency in patients without carcinoid syndrome were significantly lower $(13 \%, p<0.05)$. A more recent study by Bouma et al. [25] reported that $45 \%$ of patients, diagnosed with "serotonin-producing" NETs had low niacin levels, as tested via 24 -h urine samples. Each study utilized a different method of niacin analysis, thus complicating a clear comparison between results. Urinary excretion of N1methyl nicotinamide and its derivative N1-methyl-2-pyridone-5-carboxyamide, used in Bouma's study, is the most reliable and sensitive measure of niacin status [34].

There is limited evidence to inform when patients are most at risk of niacin deficiency with research so far only providing prevalence data from small cross-sectional samples. The prevalence and impact of biochemical or sub-clinical niacin deficiency compared to symptomatic niacin deficiency (pellagra) also requires further exploration. Shah et al. [23] reported that of the $28 \%$ of patients diagnosed with serum niacin deficiency, only 1 patient had clinical signs of pellagra. This result is similar to previous documented rates of pellagra in NET patients [33]. Up to $80 \%$ of patients with carcinoid syndrome die soon after identification of pellagra, due to the advanced stage of their NET disease [32]. This indicates that niacin deficiency and risk of pellagra worsens over time and is potentially more prevalent in patients with a prolonged history of advanced NET. Diagnosis, through assessment of clinical symptoms, may potentially be too late to provide

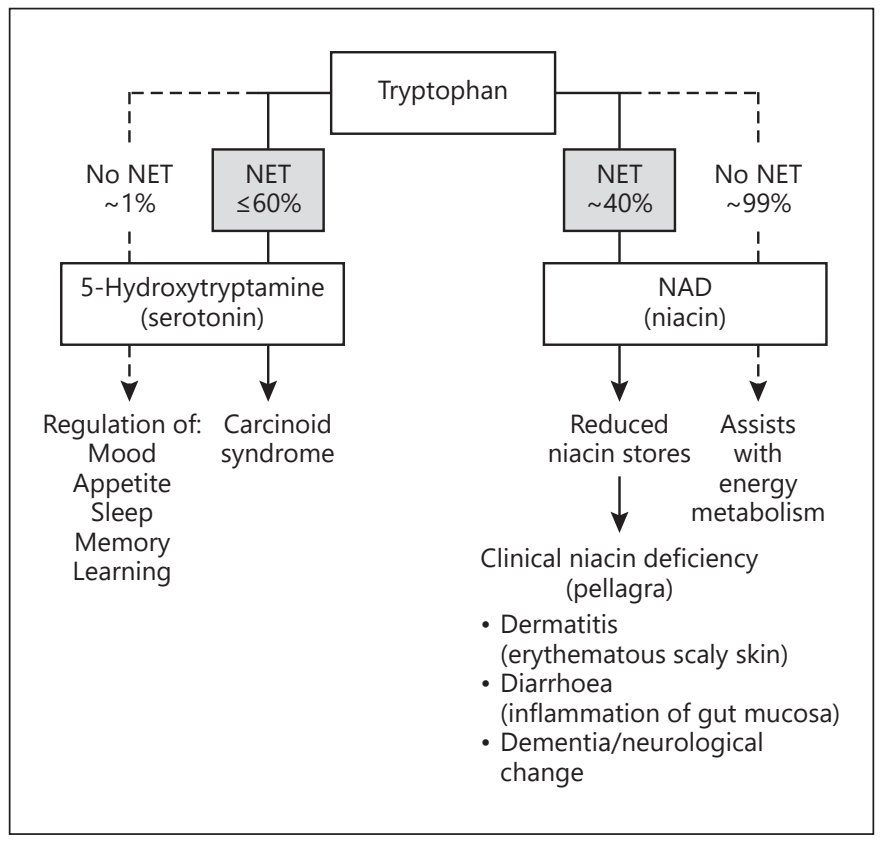

Fig. 2. Impact of NETs on niacin synthesis. NET, neuroendocrine tumor. NAD, nicotinamide adenine dinucleotide.

reversible treatment. Therefore, assessment of the underlying sub-clinical biochemical deficiency is crucial to reduce morbidity and risk of death from pellagra. Gastrointestinal symptoms of pellagra are similar to symptoms caused by the presence of a NET, and confusion regarding the cause of these symptoms risks diagnostic delay [27].

Niacin supplementation is an effective method to treat known deficiency [25]. Current best-practice guidelines 
provide little guidance to clinicians on systematic testing and management of niacin deficiency. For the general population, the recommended daily intake of niacin proposed by the Australian National Health and Medical Research Council is $14-16 \mathrm{mg} /$ day. The Carcinoid Cancer Foundation recommends $25-40 \mathrm{mg}$ twice daily niacin supplement for carcinoid patients experiencing weight loss, poor appetite, carcinoid syndrome or who have undergone previous bowel resection [35]. In the article published by Bouma et al. [25], the mean daily niacin supplementation of patients with deficiency was $144 \mathrm{mg}$ (range 3-300 mg), and supplementation in this study was reported to be effective to treat deficiency.

Interventional studies are thus required to test the optimal treatment of niacin deficiency, as well as the optimal dosing of niacin supplementation to prevent deficiency in at-risk patients. Based on current evidence it would be reasonable to recommend pro-active niacin supplementation (at least $40 \mathrm{mg} /$ day) to patients with carcinoid syndrome, and at least $100 \mathrm{mg} /$ day to patients with known niacin deficiency.

\section{Fat-Soluble Vitamins}

Diarrhea and steatorrhea are the direct side-effects of GEP NETs, as well as their surgical resection and SSA treatment; and may indicate an increased risk of excreting fat-soluble vitamins and thus subsequent deficiency [15]. SSA treatments have an anti-secretory effect by inhibiting secretion of bioactive peptides, hence reducing hormonerelated symptoms. SSA treatment can, however; influence secretion of intestinal fluid, pancreatic enzymes, and bile acids, impacting nutrient digestion and absorption processes [3, 36, 37].

Results from studies testing serum fat-soluble vitamin levels in GEP-NET patients have been conflicting, and prior to 2010 scant research had examined this phenomenon [38]. All studies used a cross-sectional design in participants with varied demographics and presentations, and measured rates of vitamin $\mathrm{D}$ deficiency ranged between 31 and $81 \%$ (Table 4) $[24,26,39-41]$. Patients with GEP NET have been shown to have lower serum vitamin $\mathrm{D}$ than healthy controls [40]. One study by Fiebrich et al. [24] tested 35 patients with metastatic mid-gut NET, who were taking SSAs for $>18$ months, and found that $80 \%$ of patients had at least one fat-soluble vitamin deficiency. The median length of time on SSA treatment for subjects was 47 months, however, no correlation was found between the length of time on treatment and the risk of deficiency [24]. SSA treatment was also associated with a lower vitamin $\mathrm{D}$ level in a larger study by Massironi et al. [40]. In these studies, most subjects had undergone previous bowel surgery, which may have increased their risk of nutrient malabsorption. Studies by Lind et al. [26] and Fiebrich et al. [24] recorded use of pancreatic enzyme replacement therapy (PERT) amongst participants (14-28\%). PERT promotes absorption of fatty acids in the small intestine and may play a role in addressing malabsorption and reversing the cause of fat-soluble vitamin deficiencies. Use of PERT is a confounding factor but was not taken into account during analysis of results in either study.

In contrast to previous studies, a study by Motylewska et al. [39] compared the prevalence of vitamin D between patients with a NET $(n=32)$ and a healthy control group. Rates of vitamin D deficiency did not differ significantly between groups ( 81 and $89 \%$, respectively), but the rates overall were considerably higher than other studies, potentially due to the exclusion of patients taking vitamin D supplementation [39]. Factors relating to dietary intake as well as seasonal variations and geography must be considered when testing vitamin $\mathrm{D}$ levels. The Australian Bureau of Statistics has reported that $23 \%$ of Australians were classified as having a vitamin D deficiency in 2011-2012 [42], a prevalence which is considerably less than in the healthy control group recruited in Motylewska et al. [39]. All studies considered seasonal variations and recorded sun exposure of participants when testing vitamin $\mathrm{D}$ levels, but did not perform subanalysis on these factors to determine the extent of their contribution.

Overall, research to date examining rates of fat-soluble vitamin deficiencies in patients with NETs, has lacked a systematic approach and has focused on small heterogeneous patient groups. More information is needed to determine whether there is an increased risk of fat-soluble vitamin deficiency in NET patients compared to general populations. Up to $28 \%$ of patients with mid-gut NET have been documented to take PERT $[24,26,43]$; however, evidence for its effectiveness and the proportion of patients with NETs that benefit from PERT remains unclear. NET patients' post-small bowel resection and/or receiving SSA treatment should be screened for diarrhea and steatorrhea. In the presence of steatorrhea, PERT should be initiated, and symptoms closely monitored. In the absence of diarrhea, it is reasonable to consider testing fat-soluble vitamins through blood samples to monitor deficiency. Oral supplementation is effective in increasing serum vitamin D levels in NET patients [26, 40,41], but evidence for the indication and effectiveness of other fat-soluble vitamin supplementation in NET patients is absent. 
Table 4. Prevalence of vitamin deficiencies in GEP NET

\begin{tabular}{|c|c|c|c|c|c|c|c|c|}
\hline \multirow[t]{2}{*}{ Study } & \multirow{2}{*}{$\begin{array}{l}\text { Vitamins } \\
\text { tested }\end{array}$} & \multirow{2}{*}{$\begin{array}{l}\text { Testing } \\
\text { method }\end{array}$} & \multirow{2}{*}{$\begin{array}{l}\text { Sample size, } \\
\text { participant } \\
\text { characteristics }\end{array}$} & \multirow[t]{2}{*}{ Study design } & \multicolumn{3}{|l|}{ Results } & \multirow{2}{*}{$\begin{array}{l}\text { Existing } \\
\text { vitamin use } \\
\text { recorded }\end{array}$} \\
\hline & & & & & niacin & vitamin $\mathrm{D}$ & other & \\
\hline $\begin{array}{l}\text { Shah et al. } \\
\text { [23], } 2005\end{array}$ & Niacin & $\begin{array}{l}\text { Blood } \\
\text { sample }\end{array}$ & $\begin{array}{l}\text { Newly diagnosed } \\
\text { carcinoid, with carcinoid } \\
\text { syndrome (CCS, } n=36 \text { ) } \\
\text { or without carcinoid syndrome } \\
\text { (CCWS, } n=32 \text { ), excluded } \\
\text { patients on SSA treatment }\end{array}$ & $\begin{array}{l}\text { Cross-sectional } \\
\text { Control group } \\
(n=24)\end{array}$ & $\begin{array}{l}\text { Niacin deficiency more } \\
\text { common in CCS patients } \\
\text { compared to controls } \\
(28 \text { vs. } 0 \%, p<0.05)\end{array}$ & & & No \\
\hline $\begin{array}{l}\text { Fiebrich et al. } \\
{[24], 2010}\end{array}$ & $\begin{array}{l}\text { Vitamins A, } \\
\text { D, E, K }\end{array}$ & $\begin{array}{l}\text { Blood } \\
\text { sample }\end{array}$ & $\begin{array}{l}\text { Metastatic midgut } \\
\text { carcinoid tumor }(n=35) \text {, all } \\
\text { treated with SSA }>18 \text { months }\end{array}$ & $\begin{array}{l}\text { Cross-sectional } \\
\text { No control group }\end{array}$ & & $\begin{array}{l}31 \% \text { vitamin } \mathrm{D} \\
\text { deficiency }\end{array}$ & $\begin{array}{l}80 \% \text { low plasma } \\
\text { level of at least } 1 \\
\text { fat-soluble vitamin } \\
32 \%>1 \text { deficiency } \\
69 \% \text { vitamin } K \\
\text { deficient }\end{array}$ & Yes \\
\hline $\begin{array}{l}\text { Bouma et al. } \\
\text { [25], } 2016\end{array}$ & Niacin & $\begin{array}{l}\text { 24-h } \\
\text { urine } \\
\text { sample }\end{array}$ & $\begin{array}{l}\text { Serotonin producing } \\
\text { NET }(n=42) \text {, Grade } 1 \text { or } \\
2,50 \% \text { small intestine } \\
\text { NET, all had received } \\
\text { niacin supplementation, } \\
79 \% \text { treated with SSA }\end{array}$ & $\begin{array}{l}\text { Retrospective cohort, } \\
\text { testing pre/post niacin } \\
\text { supplementation } \\
\text { Control group } \\
(n=133)\end{array}$ & $\begin{array}{l}\text { Niacin levels lower in } \\
\text { NET patients compared } \\
\text { to health controls (pre- } \\
\text { supplementation; } p<0.0001 \text { ) } \\
45 \% \text { of NET patients } \\
\text { had deficient niacin status } \\
\text { pre-supplementation }\end{array}$ & & & Yes \\
\hline $\begin{array}{l}\text { Lind et al. } \\
\text { [26], } 2016\end{array}$ & $\begin{array}{l}\text { Vitamin D, } \\
\text { B12 }\end{array}$ & $\begin{array}{l}\text { Blood } \\
\text { sample }\end{array}$ & $\begin{array}{l}\text { Disseminated small intestinal } \\
\text { NET ( } n=25) \text {, } \\
98 \% \text { undergone small } \\
\text { bowel resection, } 88 \% \\
\text { treated with SSA }\end{array}$ & $\begin{array}{l}\text { Cross-sectional } \\
\text { No control group }\end{array}$ & & $\begin{array}{l}46 \% \text { moderate/severe } \\
\text { vitamin D deficiency } \\
76 \% \text { low bone density } \\
\text { (DXA) }\end{array}$ & $\begin{array}{l}32 \% \text { subnormal } \\
\text { vitamin B12 } \\
(n=19)\end{array}$ & Yes \\
\hline $\begin{array}{l}\text { Motylewska } \\
\text { et al. [39], } 2016\end{array}$ & Vitamin D & $\begin{array}{l}\text { Blood } \\
\text { sample }\end{array}$ & $\begin{array}{l}\text { NET patients }(n=36) \text {, } \\
64 \% \text { GEP NET, } 53 \% \\
\text { treated with SSA }\end{array}$ & $\begin{array}{l}\text { Cross-sectional } \\
\text { Control group } \\
(n=16)\end{array}$ & & $\begin{array}{l}81 \% \text { vitamin D deficient } \\
\text { No statistically significant } \\
\text { difference compared with } \\
\text { healthy controls ( } 89 \% \\
\text { controls vitamin D } \\
\text { deficient) }\end{array}$ & & $\begin{array}{l}\text { Yes, excluded } \\
\text { from analysis }\end{array}$ \\
\hline $\begin{array}{l}\text { Massironi } \\
\text { et al. [40], } 2017\end{array}$ & Vitamin D & $\begin{array}{l}\text { Blood } \\
\text { sample }\end{array}$ & $\begin{array}{l}\text { GEP NET ( } n=138), 33 \% \text { pNET, } \\
25 \% \text { functional symptoms, } 79 \% \\
\text { previous surgery, } 44 \% \text { treated } \\
\text { with SSA }\end{array}$ & $\begin{array}{l}\text { Cross-sectional } \\
\text { Control group } \\
(n=1,232)\end{array}$ & & $\begin{array}{l}68 \% \text { vitamin D deficient } \\
\text { Patients on SSA had lower } \\
\text { vitamin D } \\
(p=0.04) \\
\text { GEP NET patients had } \\
\text { lower median vitamin D } \\
\text { than controls } \\
(p<0.0001)\end{array}$ & & $\begin{array}{l}\text { Yes, excluded } \\
\text { from analysis }\end{array}$ \\
\hline $\begin{array}{l}\text { Robbins et al. } \\
{[41], 2018}\end{array}$ & Vitamin D & $\begin{array}{l}\text { Blood } \\
\text { sample }\end{array}$ & $\begin{array}{l}\text { GEP NET ( } n=183), 62 \% \\
\text { previous surgery, } 38 \% \text { functional } \\
\text { symptoms, } 30 \% \text { treated with SSA }\end{array}$ & $\begin{array}{l}\text { Cross-sectional } \\
\text { No control group }\end{array}$ & & $\begin{array}{l}35.5 \% \text { vitamin D deficient } \\
31.3 \% \text { vitamin D } \\
\text { insufficiency }\end{array}$ & & No \\
\hline
\end{tabular}

GEP NET, gastroenteropancreatic neuroendocrine tumor; SSA, somatostatin analog.

\section{Malnutrition}

Cancer-related malnutrition is associated with increased mortality, poorer QOL, increased healthcare costs, and reduced ability to cope with the demands of treatment $[44,45]$. Patients with NETs are at risk of malnutrition due to various factors including the physical presence of cancer; paraneoplastic syndromes, disease or treatment-related symptoms; and malabsorption. Internationally, only 3 pilot studies have examined and reported on malnutrition risk or prevalence in patient's diagnosed with NETs. Overall their results have indicated that a quarter of NET patients are malnourished and up to $38 \%$ are at nutritional risk [46-48] (Table 5). All studies assessed malnutrition in a cross-sectional sample of NET patients and had similar sample sizes.
Qureshi et al. [46] found that 14\% of GEP NET outpatients were at risk of malnutrition (MUST score $\geq 1$ ) and a weak positive correlation between MUST score and treatment with SSA was found ( $p=0.013)$. Maasberg et al. [47] assessed malnutrition in inpatients with varying types of NETs $(n=203)$ using the nutritional risk screening (NRS) score and the subjective global assessment (SGA) tool. Malnutrition was diagnosed in 25\% of participants, with $21.7 \%$ diagnosed as being at "high risk of malnutrition" (NRS score $\geq 3$ ) [47]. Borre et al. [48] also assessed nutrition risk in a cross-sectional cohort of NET patients, finding 38\% scored high for nutritional risk (NRS score $\geq 3$ ). The NRS is designed to predict the probability of health outcomes in an inpatient population due to nutritional factors, including whether nutritional treatment will influence outcomes [49]. Borre et al. [48] used the NRS in an 
Table 5. Studies reporting malnutrition prevalence in NET

\begin{tabular}{|c|c|c|c|c|c|}
\hline Study & Diagnosis, sample size & Setting & $\begin{array}{l}\text { Study } \\
\text { design }\end{array}$ & $\begin{array}{l}\text { Nutritional } \\
\text { status measure }\end{array}$ & Results \\
\hline $\begin{array}{l}\text { Qureshi et al. } \\
{[46], 2016}\end{array}$ & $\begin{array}{l}\text { GEP NETs, }>40 \% \text { mid-gut NET, } 88.8 \% \text { Grade } \\
1 \text { or } 2 \text { well-differentiated GEP NET }(n=161)\end{array}$ & Outpatients & $\begin{array}{l}\text { Cross- } \\
\text { sectional }\end{array}$ & MUST & $\begin{array}{l}14 \% \text { positive MUST score }(>1) \\
\text { Weak positive correlation between MUST } \\
\text { score and treatment with SSA } \\
(p=0.013)\end{array}$ \\
\hline $\begin{array}{l}\text { Maasberg et al. } \\
\text { [47], } 2017\end{array}$ & $\begin{array}{l}33.5 \% \text { mid-gut NET, } 84.7 \% \text { Grade } 1 \text { or } 2 \\
\text { well-differentiated NET }(n=203)\end{array}$ & $\begin{array}{l}87 \% \\
\text { inpatients }\end{array}$ & $\begin{array}{l}\text { Cross- } \\
\text { sectional }\end{array}$ & SGA, NRS & $\begin{array}{l}25.1 \% \text { malnourished (SGA score B or C) } \\
21.7 \% \text { high risk of malnutrition (NRS } \\
\text { score }>3 \text { ) }\end{array}$ \\
\hline $\begin{array}{l}\text { Borre et al. } \\
{[48], 2018}\end{array}$ & $\begin{array}{l}66 \% \text { GI NET } / \mathrm{pNET}, \\
92 \% \text { Grade } 1 \text { or } 2(n=186)\end{array}$ & Outpatients & $\begin{array}{l}\text { Cross- } \\
\text { sectional }\end{array}$ & NRS, HGS & $\begin{array}{l}38 \% \text { nutritional risk (NRS score }>3 \text { ) } \\
25 \% \text { low HGS }\end{array}$ \\
\hline
\end{tabular}

MUST, malnutrition universal screening tool; SGA, subjective global assessment; NRS, nutritional risk screening tool; HGS, hand grip strength; NET, neuroendocrine tumor.

outpatient population. Also, the NRS does not provide an assessment of malnutrition or the risk of a person being malnourished. Only Maasberg et al. [47] assessed the presence of malnutrition in NET patients using a validated assessment tool. The SGA has been validated for use in hospitalized patients and oncology populations to assess malnutrition; however, other tools exist that are more sensitive to subtle changes in nutritional status, specifically in people with cancer, including the patient-generated SGA [50].

These studies have demonstrated the existence and potential prevalence of malnutrition in people with a GEP NET; however, further research is required to determine individual or treatment-related factors associated with increase risk of malnutrition, and how it changes during the disease course. The proportion of patients with Grade 1 or 2 NETs was high in all studies (84.7-92\%), potentially resulting in lower reported rates of malnutrition [47]. NETs histologically classified as Grade 1 or 2 are traditionally slower to progress and less aggressive in nature [51]; although on the contrary they are also more likely to have hormonal secretory syndromes and undergo bowel resection. Maasberg et al. [47] reported that patients with Grade 3 disease had a significantly higher prevalence of malnutrition than patients with Grade 1 or 2 disease (57.9 and $22.1 \%$ respectively, $p=0.002$ ). As expected, patients with Grade 3 NETs, have aggressive and often more advanced disease and a greater preponderance to undergo treatment with chemotherapy. In the same study, patients with progressive disease of all grades and those receiving treatment with chemotherapy at the time of assessment also had higher prevalence rates of malnutrition, which was statistically significant [47]. Borre et al. [48] was the only study to assess patient-reported symptom burden and found that patients at nutri- tional risk (NRS $\geq 3$ ) more frequently reported symptoms such as nausea, vomiting, stomach ache, and poor appetite.

Patients with GEP NETs who are malnourished are at higher risk of complications and mortality [47, 52]. Maasberg et al. [47] found that malnourished patients had significantly shorter overall survival (19.94 vs. 31.17 months, $p<0.001)$ and significantly longer length of stay than well-nourished patients ( 8.8 vs. 4.0 days respectively, $p<$ $0.001)$. In a study by Glazer et al. [52], which analyzed data on 22,096 discharged NET patients using the United States nationwide inpatient sample database, malnutrition was associated with a higher risk of inpatient mortality ( 9 vs. $2 \%, p<0.0005)$ and higher complication rate (15 vs. $10 \%, p<0.0005)$. This study relied on classification of malnutrition via IDC-9 coding, therefore limiting detail available on the method of malnutrition diagnosis and other relevant patient data such as weight and BMI [52].

Thus all cancer patients should be screened for risk of malnutrition on diagnosis and during treatment, including patients diagnosed with a NET. The most appropriate nutrition interventions to address malnutrition in NET patients has not been studied, therefore interventional studies testing methods of nutrition therapy in NET patients is warranted.

\section{Dietary Habits and Food Intolerance}

Recent reviews have documented the importance of an individualized approach to nutrition management for patients with GEP NETs $[11,12,38,53]$. In the absence of any symptoms, patients with a GEP NET are encouraged to follow healthy dietary guidelines as recommended for the general population $[12,38]$. When symptoms are present and impact the function and QOL, there may be 
a role for diet modification; however, there is limited research to guide interventions in this situation.

A large multinational survey conducted by Singh et al. [17] found that more than half of participants $(n=1,118$, $58 \%)$ reported making dietary changes as a result of their NET. Food intolerance was reported by $89 \%(n=33)$ of participants with a NET of the gastrointestinal tract in another study published in 2013, and was more frequently reported than other symptoms including diarrhea $(n=$ $13,35 \%)$ and fatigue $(n=13,35 \%)$ [14]. These studies provide only limited data and type of food intolerance or dietary change and the actual rationale for the diagnosis of food intolerance was not explored. Nevertheless, it does highlight the considerable impact NETs can have on dietary intake and hence the potential relationship between symptoms and diet.

Only 4 published studies have reported data on dietary habits amongst patients with NETs [11,26, 54, 55]. Studies by Gallo et al. [11] and Barrea et al. [55] have demonstrated that poor adherence to a Mediterranean style diet may correlate with increased NET severity or aggressiveness. The Mediterranean diet incorporates several healthy eating principles, including high fruit and vegetable intake and low saturated fat intake, considered optimal for good health and reduced disease burden. Only asymptomatic or disease-free patients with Grade 1 and 2 NETs were sampled for these studies and therefore results cannot be generalized to all NETs. Lind et al. [26] examined a small group of patients with mid-gut NETs and found that 36\% $(n=9)$ reported to avoid either fermentable carbohydrates or fatty foods in an attempt to control symptoms of flatulence and diarrhea. In a qualitative study of 9 patients by Davies and Caplin [54], (published abstract), all patients reported restricting their diet and reducing meal sizes due to symptoms of their NET. Details of sampling approach, participant characteristics and methodology of some of these studies are limited, but results suggest that attention to diet and dietary habits are important to identify dietary restrictions which may impact the overall context of care for people with NETs. Patients with a NET, particularly those with carcinoid syndrome, are commonly misdiagnosed with other conditions such as irritable bowel syndrome, diverticular disease, food allergies or intolerances when presenting with generalized gastrointestinal symptoms such as diarrhea, abdominal discomfort, and pain [56]. Treatment for these conditions regularly involves dietary modification, which may be unnecessary or inappropriate if the underlying cause of these symptoms is due to a NET.

There is an absence of robust evidence regarding the dietary habits of patients with NETs and their impact on symptoms and QOL. The Carcinoid Cancer Foundation, a national non-profit organization in the United States, documented results on their website from a survey of NET patients $(n=97)$ in 1999 , of which $43 \%$ had a small intestine NET and 79\% had undergone intestinal resection [35]. Common dietary factors identified by these patients to trigger a reaction or "carcinoid crisis" (such as flushing or diarrhea) included eating a large meal, alcohol, tomato dishes, fatty foods, coffee/caffeine, chocolate, nuts, and spicy foods. In nutrition guidelines published online by The Carcinoid Cancer Foundation and other NET groups, patients with NETs are recommended to reduce consumption of foods containing amines, in an attempt to diminish symptoms of carcinoid syndrome [35]. There is currently no published evidence of a correlation between dietary amines and symptoms of carcinoid syndrome, and information at this stage remains anecdotal.

\section{Nutrition within Clinical Guidelines}

National and international clinical practice and consensus guidelines summarizing current evidence are available to clinicians and provide direction on diagnostic and medical aspects of NET patient care. These guidelines were developed by specialist professional groups including the North American Neuroendocrine Tumor Society, European Neuroendocrine Tumor Society and the European Society for Medical Oncology $[1,13,37,57,58]$. The importance of multidisciplinary collaboration and management of NETs is emphasized in some of these guidelines $[1,3,5,13]$; this is mostly defined as a combination of various medical disciplines; such as medical oncology, surgical oncology, nuclear medicine, or endocrinology; specialized nursing input and links with NET patient support groups. The value of specialized nursing input and links with NET patient support groups is also highlighted in some clinical guidelines [6]. Regardless, the essential role of allied health professionals, such as dietitians and other clinicians providing supportive care has not been addressed or highlighted in NET research and guidelines. The majority of nutritional information available is online, from a range of sources, including public hospitals, NET support groups and organizations [35, 59-61], and appears to be based mostly on anecdotal evidence with limited published research available to support these recommendations.

Based on evidence available with regard to nutritional complications of GEP NETs, recommendations for clinical practice and suggestions for further research are summarized in Table 6. 
Table 6. Summary of recommendations for nutrition management and further research

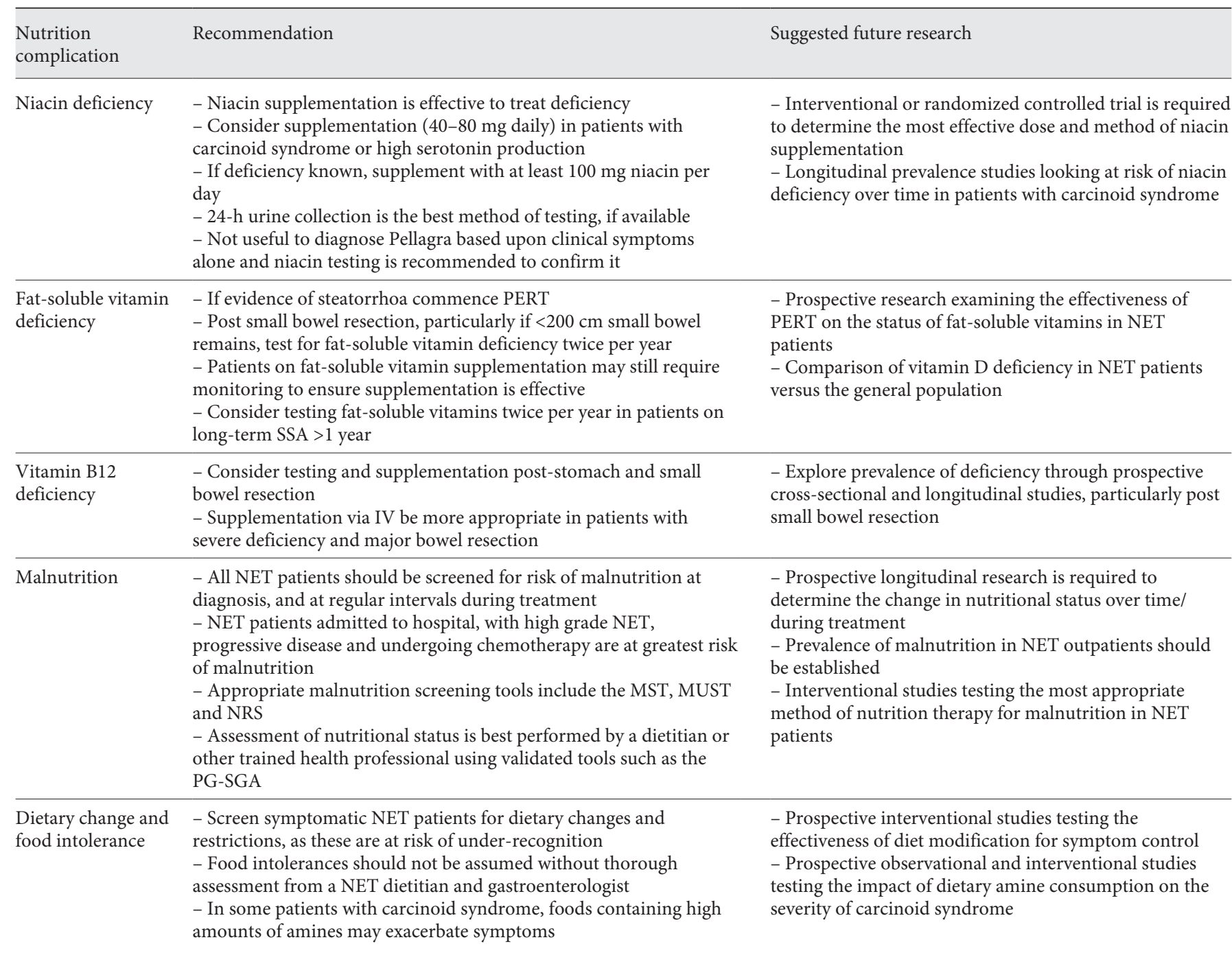

PERT, pancreatic enzyme replacement therapy; NET, neuroendocrine tumor; SSA, somatostatin analogue; MST, malnutrition screening tool; MUST, malnutrition universal screening tool; NRS, nutrition risk screen; PG-SGA, patient generated subjective global assessment.

\section{Conclusion and Recommendations}

GEP NET are a heterogeneous group of tumors that have a distinct impact on patient's morbidity and QOL due to the tumor location, general effects of malignancy, hormonal hyper-secretion, and treatment. Malnutrition, vitamin deficiencies, and food intolerances are prevalent but currently under recognized in this population. If left untreated, these complications can significantly impact on patient's QOL, physical function, and survival. There are significant gaps in knowledge with regards to screen- ing for malnutrition, dietary modification, and nutritional deficiencies in this patient group. Despite this, a validated tool should be used for malnutrition screening with all NET patients, and prophylactic supplementation and testing for vitamin deficiency in at-risk NET patients should be considered as part of standard care. Further large cross-sectional and longitudinal studies are required to better understand the nutritional impact of these complex tumors and to underpin the development of evidence-based nutrition guidelines for patients with GEP NETs. 


\section{Statement of Ethics}

The authors have no ethical conflicts to disclose.

\section{Disclosure Statement}

E.L. is a PhD student at The University of Melbourne, Australia. The authors indicate no other potential conflicts of interest.

\section{Funding Sources}

This work was supported by funding received from the Victorian Cancer Agency, Victorian Government, Melbourne, Australia; Austin Health, Melbourne, Australia; Ipsen, Australia; and
Unicorn Foundation, Australia. E.L. received funding from the Victorian Cancer Agency and Austin Health towards their PhD stipend and research costs. E.L. received funding from Ipsen Australia and Unicorn Foundation Australia towards $\mathrm{PhD}$ research costs, not related to this particular manuscript. Funding sources were not involved in the conception, preparation or writing of this manuscript.

\section{Author Contributions}

E.L. conceived and designed the manuscript with assistance from M.K., M.M., and N.K. E.L. analyzed and interpreted the literature and drafted the manuscript. All authors revised it critically for important intellectual content, and approved the final version for submission.

\section{References}

1 Kunz PL, Reidy-Lagunes D, Anthony LB, Bertino EM, Brendtro K, Chan JA, et al.; North American Neuroendocrine Tumor Society. Consensus guidelines for the management and treatment of neuroendocrine tumors. Pancreas. 2013 May;42(4):557-77.

2 Dasari A, Shen C, Halperin D, Zhao B, Zhou $\mathrm{S}, \mathrm{Xu} \mathrm{Y}$, et al. Trends in the Incidence, Prevalence, and Survival Outcomes in Patients With Neuroendocrine Tumors in the United States. JAMA Oncol. 2017 Oct;3(10):133542.

3 Modlin IM, Moss SF, Oberg K, Padbury R, Hicks RJ, Gustafsson BI, et al. Gastrointestinal neuroendocrine (carcinoid) tumours: current diagnosis and management. Med J Aust. 2010 Jul;193(1):46-52.

4 Modlin IM, Lye KD, Kidd M. A 5-decade analysis of 13,715 carcinoid tumors. Cancer. 2003 Feb;97(4):934-59.

5 Singh S, Asa SL, Dey C, Kennecke H, Laidley $\mathrm{D}$, Law $\mathrm{C}$, et al. Diagnosis and management of gastrointestinal neuroendocrine tumors: an evidence-based Canadian consensus. Cancer Treat Rev. 2016 Jun;47:32-45.

6 Ramage JK, Ahmed A, Ardill J, Bax N, Breen DJ, Caplin ME, et al.; UK and Ireland Neuroendocrine Tumour Society. Guidelines for the management of gastroenteropancreatic neuroendocrine (including carcinoid) tumours (NETs). Gut. 2012 Jan;61(1):6-32.

7 Burgess A. Diagnosing, treating and managing carcinoid tumours. Nurs Times. 2005 Jul; 101(29):32-4

8 Kaupp-roberts S, Srirajaskanthan R, Ramage JK. Symptoms and Quality of Life in Gastroenteropancreatic Neuroendocrine Tumours. EMJ Oncol. 2015;3:34-40.

9 Gustafsson BI, Hauso O, Drozdov I, Kidd M, Modlin IM. Carcinoid heart disease. Int J Cardiol. 2008 Oct;129(3):318-24.
10 Pearman TP, Beaumont JL, Cella D, Neary MP, Yao J. Health-related quality of life in patients with neuroendocrine tumors: an investigation of treatment type, disease status, and symptom burden. Support Care Cancer. 2016 Sep;24(9):3695-703.

11 Gallo M, Muscogiuri G, Pizza G, Ruggeri RM, Barrea L, Faggiano A, et al. The management of neuroendocrine tumours: A nutritional viewpoint. Crit Rev Food Sci Nutr. 2019; 59(7):1046-57.

12 Altieri B, Barrea L, Modica R, Muscogiuri G, Savastano S, Colao A, et al. Nutrition and neuroendocrine tumors: an update of the literature. Rev Endocr Metab Disord. 2018 Jun; 19(2):159-67.

13 Öberg K, Knigge U, Kwekkeboom D, Perren A; ESMO Guidelines Working Group. Neuroendocrine gastro-entero-pancreatic tumors: ESMO Clinical Practice Guidelines for diagnosis, treatment and follow-up. Ann Oncol. 2012 Oct;23 Suppl 7:vii124-30.

14 Haugland T, Veenstra M, Vatn M, Wahl A. Improvement in Stress, General Self-Efficacy, and Health Related Quality of Life following Patient Education for Patients with Neuroendocrine Tumors: A Pilot Study. Nurs Res Pract. 2013;2013:695820.

15 van der Horst-Schrivers AN, Wymenga AN, Links TP, Willemse PH, Kema IP, de Vries EG. Complications of midgut carcinoid tumors and carcinoid syndrome. Neuroendocrinology. 2004;80 Suppl 1:28-32.

16 Vinik AI, Woltering EA, Warner RR, Caplin M, O’Dorisio TM, Wiseman GA, et al.; North American Neuroendocrine Tumor Society (NANETS). NANETS consensus guidelines for the diagnosis of neuroendocrine tumor. Pancreas. 2010 Aug;39(6):713-34.
17 Singh S, Granberg D, Wolin E, Warner R, Sissons M, Kolarova T, et al. Patient-Reported Burden of a Neuroendocrine Tumor (NET) Diagnosis: Results From the First Global Survey of Patients With NETs. J Glob Oncol. 2016 Jun;3(1):43-53.

18 Ter-Minassian M, Chan JA, Hooshmand SM, Brais LK, Daskalova A, Heafield R, et al. Clinical presentation, recurrence, and survival in patients with neuroendocrine tumors: results from a prospective institutional database. Endocr Relat Cancer. 2013 Mar;20(2):187-96.

19 Fröjd C, Larsson G, Lampic C, von Essen L. Health related quality of life and psychosocial function among patients with carcinoid tumours. A longitudinal, prospective, and comparative study. Health Qual Life Outcomes. 2007 Apr;5(1):18.

20 Haugland T, Vatn MH, Veenstra M, Wahl AK, Natvig GK. Health related quality of life in patients with neuroendocrine tumors compared with the general Norwegian population. Qual Life Res. 2009 Aug;18(6):719-26.

21 Beaumont JL, Cella D, Phan AT, Choi S, Liu Z, Yao JC. Comparison of health-related quality of life in patients with neuroendocrine tumors with quality of life in the general US population. Pancreas. 2012 Apr; 41(3):461-6.

22 Larsson G, Haglund K, Von Essen L. Distress, quality of life and strategies to 'keep a good mood' in patients with carcinoid tumours: patient and staff perceptions. Eur J Cancer Care (Engl). 2003 Mar;12(1):46-57.

23 Shah GM, Shah RG, Veillette H, Kirkland JB, Pasieka JL, Warner RR. Biochemical assessment of niacin deficiency among carcinoid cancer patients. Am J Gastroenterol. 2005 Oct;100(10):2307-14. 
24 Fiebrich HB, Van Den Berg G, Kema IP, Links TP, Kleibeuker JH, Van Beek AP, et al. Deficiencies in fat-soluble vitamins in long-term users of somatostatin analogue. Aliment Pharmacol Ther. 2010 Dec;32(11-12):1398404.

25 Bouma G, Van Faassen M, Kats-Ugurlu G, de Vries EG, Kema IP, Walenkamp AM. Niacin (Vitamin B3) Supplementation in Patients with Serotonin-Producing Neuroendocrine Tumor. Neuroendocrinology. 2016;103:48994.

26 Lind A, Wängberg B, Ellegård L. Vitamin D and vitamin B12 deficiencies are common in patients with midgut carcinoid (SI-NET). Eur J Clin Nutr. 2016 Sep;70(9):990-4.

27 Hegyi J, Schwartz RA, Hegyi V. Pellagra: dermatitis, dementia, and diarrhea. Int J Dermatol. 2004 Jan;43(1):1-5.

28 Le Floc'h N, Otten W, Merlot E. Tryptophan metabolism, from nutrition to potential therapeutic applications. Amino Acids. 2011 Nov 41(5):1195-205.

29 Fleischmajer R, Hyman AB. Clinical significance of derangements of tryptophan metabolism. A review of pellagra, carcinoid and $\mathrm{H}$ disease. Arch Dermatol. 1961 Oct;84(4):56373.

30 Castiello RJ, Lynch PJ. Pellagra and the carcinoid syndrome. Arch Dermatol. 1972 Apr; 105(4):574-7.

31 Bender DA. Biochemistry of tryptophan in health and disease. Mol Aspects Med. 1983; 6(2):101-97.

32 Bell HK, Poston GJ, Vora J, Wilson NJ. Cutaneous manifestations of the malignant carcinoid syndrome. Br J Dermatol. 2005 Jan 152(1):71-5.

33 Bax ND, Woods HF, Batchelor A, Jennings M. Clinical manifestations of carcinoid disease. World J Surg. 1996 Feb;20(2):142-6.

34 NHMRC NH and MRC. Niacin. Nutr. Ref. Values Aust. New Zeal. Incl. Recomm. Diet. Intakes; 2006. pp. 79-84.

35 Warner ME. Nutritional Concerns For The Carcinoid Patient: Developing Nutrition Guidelines For Persons With Carcinoid Disease. Carcinoid Cancer Found 2008. [accessed January 19, 2017]. Available from: http://www.carcinoid.org/for-patients/general-information/nutrition/nutritional-concerns-for-the-carcinoid-patient-developingnutrition-guidelines-for-persons-with-carcinoid-disease/.

36 Akerström G, Hellman P, Hessman O, Osmak L. Management of midgut carcinoids. J Surg Oncol. 2005 Mar;89(3):161-9.

37 Pavel M, Valle JW, Eriksson B, Rinke A, Caplin M, Chen J, et al.; Antibes Consensus Conference Participants; Antibes Consensus Conference participants. ENETS Consensus Guidelines for the Standards of Care in Neuroendocrine Neoplasms: Systemic Therapy Biotherapy and Novel Targeted Agents. Neuroendocrinology. 2017;105(3):266-80.
38 Go VL, Srihari P, Kamerman Burns LA. Nutrition and gastroenteropancreatic neuroendocrine tumors. Endocrinol Metab Clin North Am. 2010 Dec;39(4):827-37.

39 Motylewska E, Gawronska J, Niedziela A, Melen-Mucha G, Lawnicka H, Komorowski J, et al. Somatostatin Analogs and Tumor Localization Do Not Influence Vitamin D Concentration in Patients with Neuroendocrine Tumors. Nutr Cancer. 2016;68(3):428-34.

40 Massironi S, Zilli A, Bernasconi S, Fanetti I, Cavalcoli F, Ciafardini C, et al. Impact of $\mathrm{Vi}$ tamin D on the Clinical Outcome of GastroEntero-Pancreatic Neuroendocrine Neoplasms: Report on a Series from a Single Institute. Neuroendocrinology. 2017; 105(4): 403-11.

41 Robbins HL, Symington M, Mosterman B, Goodby J, Davies L, Dimitriadis GK, et al. Supplementation of Vitamin D Deficiency in Patients with Neuroendocrine Tumors Using Over-the-Counter Vitamin D3 Preparations. Nutr Cancer. 2018 Jul;70(5):748-54.

42 Australian Health Survey: Biomedical results for nutrients, 2011 - 2012. Vitamin D. Aust Bur Stat 2014. [accessed November 4, 2016]. Available from: http://www.abs.gov.au/ausstats/abs@.nsf/Lookup/4364.0.55.006Chapt er2002011-12.

43 Lindholm EB, Gupta MK, Boudreaux JP, Burns LA, Wang YZ, Woltering EA. The incidence of over-the-counter medication use in patients with midgut neuroendocrine tumors. Am Surg. 2015 Mar;81(3):278-81.

44 Arends J, Bodoky G, Bozzetti F, Fearon K, Muscaritoli M, Selga G, et al.; DGEM (German Society for Nutritional Medicine); ESPEN (European Society for Parenteral and Enteral Nutrition). ESPEN Guidelines on Enteral Nutrition: non-surgical oncology. Clin Nutr. 2006 Apr;25(2):245-59.

45 Nitenberg G, Raynard B. Nutritional support of the cancer patient: issues and dilemmas. Crit Rev Oncol Hematol. 2000 Jun;34(3):13768.

46 Qureshi SA, Burch N, Druce M, Hattersley JG, Khan S, Gopalakrishnan K, et al. Screening for malnutrition in patients with gastroentero-pancreatic neuroendocrine tumours: a cross-sectional study. BMJ Open. 2016 May; 6(5): 010765

47 Maasberg S, Knappe-Drzikova B, Vonderbeck D, Jann H, Weylandt KH, Grieser C, et al. Malnutrition Predicts Clinical Outcome in Patients with Neuroendocrine Neoplasia. Neuroendocrinology. 2017;104(1):11-25.

48 Borre M, Dam GA, Knudsen AW, Grønbaek $\mathrm{H}$. Nutritional status and nutritional risk in patients with neuroendocrine tumors. Scand J Gastroenterol. 2018 Mar;53(3):284-92.

49 Kondrup J, Rasmussen HH, Hamberg O, Stanga Z; Ad Hoc ESPEN Working Group. Nutritional risk screening (NRS 2002): a new method based on an analysis of controlled clinical trials. Clin Nutr. 2003 Jun;22(3):32136.
50 Bauer J, Capra S, Ferguson M. Use of the scored Patient-Generated Subjective Global Assessment (PG-SGA) as a nutrition assessment tool in patients with cancer. Eur J Clin Nutr. 2002 Aug;56(8):779-85.

51 Klimstra DS, Modlin IR, Coppola D, Lloyd $\mathrm{RV}$, Suster S. The pathologic classification of neuroendocrine tumors: a review of nomenclature, grading, and staging systems. Pancreas. 2010 Aug;39(6):707-12.

52 Glazer E, Stanko K, Ong E, Guerrero M. Decreased inpatient mortality in obese patients with abdominal nets. Endocr Pract. 2014, Epub ahead of print.

53 Weickert MO. Should malnutrition screening be routine for patients with GEP-NET? Int I Endocr Oncol. 2016;3(3):197-201.

54 Davies P, Caplin ME. Carciniod patients' experiences of the influence of diet and their symptoms. Neuroendocrinology. 2009;90: 93-146.

55 Barrea L, Altieri B, Muscogiuri G, Laudisio D, Annunziata G, Colao A, et al. Impact of Nutritional Status on Gastroenteropancreatic Neuroendocrine Tumors (GEP-NET) Aggressiveness. Nutrients. 2018 Dec 10(12):E1854.

56 Toth-Fejel S, Pommier RF. Relationships among delay of diagnosis, extent of disease, and survival in patients with abdominal carcinoid tumors. Am J Surg. 2004 May;187(5): 575-9.

57 Delle Fave G, O'Toole D, Sundin A, Taal B, Ferolla P, Ramage JK, et al.; Vienna Consensus Conference participants. ENETS Consensus Guidelines Update for Gastroduodenal Neuroendocrine Neoplasms. Neuroendocrinology. 2016;103(2):119-24.

58 Falconi M, Eriksson B, Kaltsas G, Bartsch DK, Capdevila J, Caplin M, et al.; Vienna Consensus Conference participants. ENETS Consensus Guidelines Update for the Management of Patients with Functional Pancreatic Neuroendocrine Tumors and Non-Functional Pancreatic Neuroendocrine Tumors. Neuroendocrinology. 2016;103(2):153-71.

59 Whyand T, Davies P, Caplin M. Food and Neuroendocrine Tumours (NETs). R Free Hosp Neuroendocr Tumour Unit 2014. [accessed January 19, 2017]. Available from: http://s3-eu-west-1.amazonaws.com/files. royalfree.nhs.uk/Patient_resources/NETs/ Food_and_NETs.pdf.

60 Hassell M, Warner ME. Nutrition and Carcinoid. Carcinoid Cancer Found 2006. [accessed January 19, 2017]. Available from: http://www.carcinoid.org/wp-content/uploads/2015/10/Miles-_Carcinoid_Nutrition_9_2006.pdf.

61 Dyer D, Ryan A. Carcinoid Syndrome and Diet. Oncol Nutr Acad Nutr Diet 2014. [accessed January 19, 2017]. Available from: http://www.oncologynutrition.org/erfc/eating-well-when-unwell/carcinoid-syndromeand-diet/. 